\title{
EL BOCETO Y LA INFORMACIÓN. GOYA Y LAS PINTURAS DE SAN FRANCISCO DE BORJA ENTRE LA IMAGINACIÓN Y LAS FUENTES TEXTUALES
}

\author{
POR \\ RAINALD RAABE \\ München
}

\begin{abstract}
Goya's lateral paintings of the Borja-chapel at Valencia cathedral deserve some attention: First they present themes without any iconographic forevunner. On the other side for these laterals there are preserved as an exception in Goya's œuvre not only two preparatory drawings but two oilsketches as well. So the different stages from the first idea to the finished paintings are to be well persecuted. Precise investigation of the compositions proves that Goya kept the general disposition from the beginning, whereas he changed the compositions in part between drawings and oilsketches. There is some evidence that while working Goya got to know and followed a particular biography on the Borja-saint, a text by the Jesuit-Cardinal Cienfuegos. Moreover the unique choice of scenes is to be interpreted as a cautious wangling out of a dilemma: Goya's patrons and the appropriate representation of their family-saint on one side and the political situation after the expulsion of the jesuits in late eighteenth-century Spain on the other.
\end{abstract}

Las pinturas de temas religiosos de Goya no se han tenido en cuenta en mucho tiempo y sólo en los últimos años se les concede la importancia que les corresponde. En 1946 se publicaron dos artículos referentes a su pintura religiosa, pero estos estudios sólo trataban problemas estilísticos o se referían a las fuentes documentales ${ }^{1}$. Hasta 1990 las obras generales dedicadas a la obra de Goya sólo incluían capítulos obligatorios y concisos con respecto a su pintura religiosa; en este año se publicó la monografía de Morales y Marín dedicada específicamente a la pintura religiosa de Goya. Aunque casi todos los cuadros de tema religioso fueron catalogados y comentados ${ }^{2}$, pensamos que hay aspectos en los que se puede ahondar y que se refieren al ingenio de Goya, sus fuentes y al significado de sus invenciones.

Cuando Goya recibió el encargo de decorar los laterales de la capilla familiar de los Osuna con dos pinturas dedicadas a episodios de la vida de S. Francisco de Borja, se vio enfrentado a

\footnotetext{
1 Francisco Javier Sánchez CANTón: «Goya, pintor religioso», en Revista de Ideas Estéticas IV, 1946, pp. 277-306; ENRIQue Lafuente Ferrari: «Sobre el cuadro de San Francisco el Grande y las ideas estéticas de Goya», en Revista de Ideas Estéticas IV, 1946, pp. 307-338.

2 José Morales y MARín: «Goya, pintor religioso», Zaragoza, 1990. A continuación se utilizarán abreviaturas al remitirnos a bibliografía utilizada reiterativamente nombrando sólo el autor y el año de publicación.
} 
un doble desafío respecto a sus comitentes, para ellos ya había realizado varias obras y, después de la muerte del infante don Luis, se convirtieron en sus mecenas más importantes en la segunda mitad de los años 80 y principios de los 90 del siglo XVIII ${ }^{3}$. Por otro lado se enfrentaba a un desafío artístico, no tanto por tener que competir con el pintor de cámara, Mariano Salvador Maella, que había recibido el encargo para la pintura del altar de la capilla ${ }^{4}$, sino porque se enfrentaba a unos temas singulares que carecían de antecedentes iconográficos. Mientras que el tema del retablo del altar mayor ya era conocido por obras teatrales piadosas en el siglo XVII ${ }^{5}$, los temas que debía tratar Goya eran excepcionales.

Como no se ha encontrado ninguna nota escrita referente al encargo, los títulos de los cuadros resultan imprecisos, ya que no se ha conservado ninguna fuente escrita que se refiera al encargo. Los títulos son posteriores, como la mayoría de las designaciones que se han aplicado a las obras de Goya, y en los últimos ciento cincuenta años se han afianzado con ligeras variantes ${ }^{6}$. Con ello se ha oscurecido la pregunta a propósito de los contenidos y mensajes de estos dos cuadros, de los cuales se han conservado dibujos, bocetos al óleo y el cuadro definitivo $^{7}$, lo que ya en sí resulta ser excepcional en la obra conservada de Goya ${ }^{8}$. Por ello se da la posibilidad de seguir el camino de la primera idea hasta la obra acabada (figs. 1 a 6 ).

${ }^{3}$ Pierre Gassier / Juliet Wilson: «Goya, Leben und Werk», Fribourg, 1971, pp. 64 sigs. y n. ${ }^{\text {os }} 219,220,248-255,278$ Esta obra capital de Gassier/Wilson se abreviará de la siguiente manera: GW 1971. Véase también José MANUEL PITA ANDRADE: «Goya en su vida y en las obras de la exposición», en Realidad e Imagen. Goya 1746-1828. Catálogo de la exposición, Museo de Zaragoza, 3 de octubre-1 de diciembre 1996, Madrid, 1996, pp. 35 y sigs.

${ }^{4}$ El adjudicar la decoración de iglesias y capillas a varios pintores a la vez es un hecho común. Goya, p. ej., trabajaba junto a Maella, Bayeu y otros pintores en la decoración de S. Francisco el Grande en Madrid; Goya y Bayeu en Zaragoza y en Sta. Ana de Valladolid.

5 Así, antes de su canonización: Scena De mortue Isabellae Augustae a Francisco Borgia Duce Gandiae salubriter olim spectata nunc in theatrum educta, Gymnas. Soc. Jes., Landsberg, 1666.

${ }^{6}$ En la factura de Goya se lee: «... dos cuadros que ha pintado representativos de pasajes de la vida de San Fran. ${ }^{\text {co }}$ de Borja». GW 1971, p. 383. Ya Valentín Carderera: «François Goya. Sa vie, ses dessins et ses eaux-fortes», en Gazette des Beaux Arts, serie I, tomo 7, 1860, p. 222, hace mención del dibujo con la representación de la cama del enfermo como «Damné avec Saint Francis de Borja»; Charles YRIARTE, Goya. Sa biographie, les fresques, les toiles, les tapisseries, les eaux-fortes et le catalogue de l'œuvre, Paris, 1867, p. 66, nombra como tema de los cuadros: «"Le marquis de Lombay, duc de gandía, prêt à quitter le monde pour s'enfermer dans un clôitre, fait ses adieux à sa famille" y "Saint François présente le crucifix à un moribond qui persiste dans l'impénitence finale, et la sainte image confirme avec son sang la réprobation qui s'attache à l'impénitence"». Estas calificaciones las repite de forma abreviada en la parte del catálogo, p. 129: «Saint François de Borja fait ses adieux à sa famille» y «Le Saint au lit d'un moribond»; Cipriano Muñoz y MANZANO DE LA ViÑaZA, Goya, su tiempo, su vida, sus obras, Madrid, 1897, pp. 200 ss., califica los dos cuadros con «El Marqués de Lombay despidiéndose de su familia para entrar en la Compañía de Jesús» y «San Francisco de Borja asistiendo á un moribundo impenitente». Mientras que en GW 1971, n. ${ }^{\circ}$ 245, y Juliet Wilson-Bareau: Pinturas de tema religioso, 1780-1788, en Juliet Wilson-Bareau y Manuela B. Mena Marqués (ed.), Goya. El Capricho y la Invención. Cuadros de gabinete, bocetos y miniaturas. Catálogo de la exposición, Madrid, 1993, p. 146, utilizan estos calificativos Folke NordSTRÖM: Goya. Saturn and Melancholy. Acta Universalitatis Upsaliensis, Figura Nova Series 3, Stockholm, 1962, pp. 59 sig., propuso para cada cuadro dos títulos: "Francisco de Borja, Marquéz de Lomay (sic!), Duque de Borja and Future Saint, Taking Leave of his Family upon Entering the Jesuit Order (La despedida de San Francisco de Borja de su familia)" and "San Frrancisco de Borja Exorcising an Evil Spirit from an Impenitent Dying Man (San Francisco de Borja y el moribundo impenitente)"». José CAMón Aznar: Francisco de Goya, tomo II, Zaragoza, 1981, p. 62, también menciona dos títulos, «el moribundo blasfemo» y «El moribundo impenitente», con la osada aseveración «tema predilecto de la iconografía jesuítica». JosÉ GuDIOL, Goya, 1746-1828, Biography, Analytical Study and Catalogue of his paintings, 2 vols. Barcelona, 1985, I, p. 104, n. ${ }^{\circ} 243$, le dio el título de forma más precavida como «Saint Francis of Borgia attending a dying man». Morales y Marín, 1990, p. 205 y sigs., también se atiene a esta designación. La nota marginal en el modelo de dibujo en El Prado lo designa simplemente «El Condenado. Primer pensamiento de Goya para el cuadro de la Cat. de Valencia», de lo cual se puede deducir que esta nota sólo pudo ser puesta después de terminada la obra. Además, el calificativo de «condenado» del dibujo con respecto a la escena representada no es correcta. Ya que el demonio está huyendo. Véase más adelante.

7 Con respecto a los dos dibujos, véase Pierre Gassier, Francisco Goya. Les Dessins de Goya, tomo II, Fribourg, 1975, n. ${ }^{\circ} 12$ y 13, pp. 41 sigs.; la última vez que los bocetos fueron comentados: Juliet WILSON-BAREAU, Pinturas de tema religioso 1780-1788, en: Juliet Wilson-Bareau y Manuela B. Mena Marqués (ed.), Goya. El Capricho y la Invención. Cuadros de gabinete, bocetos y miniaturas. Catálogo de la exposición, Madrid, 1993, pp. 125-151, véase pp. 146 y sigs.; los cuadros de la catedral de Valencia comentados en José Morales y MARín, 1990, pp. 202 sigs.

${ }^{8}$ El pequeño cuadro que Morales y Marín, 1990, pp. 198 sigs., n. ${ }^{\circ} 79$, puso al alcance de los investigadores se debe eliminar de la obra de Goya. No hay ni un solo esbozo al óleo de Goya que no haya cambiado más o menos el trazado de 


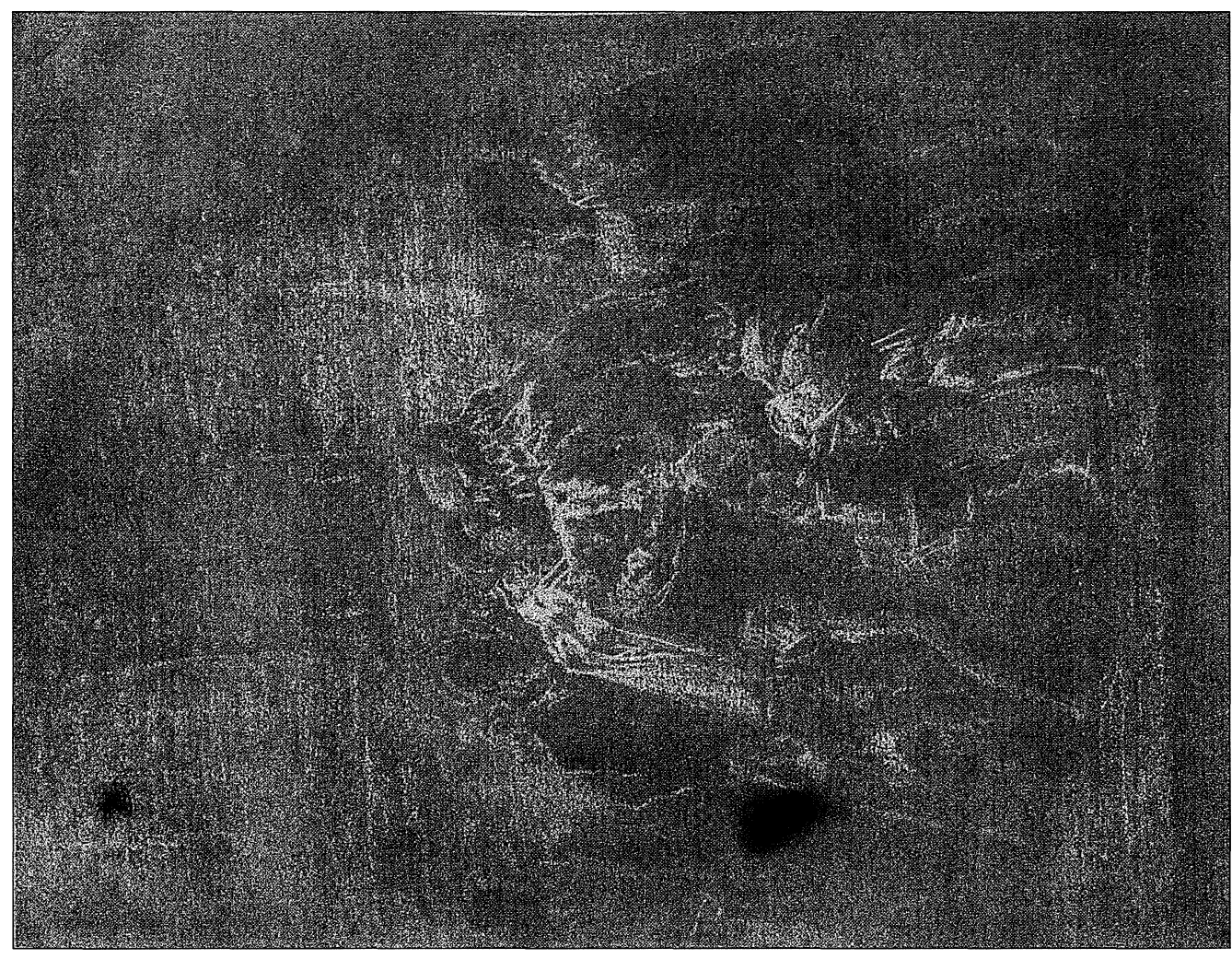

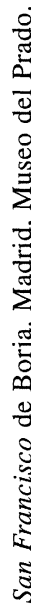

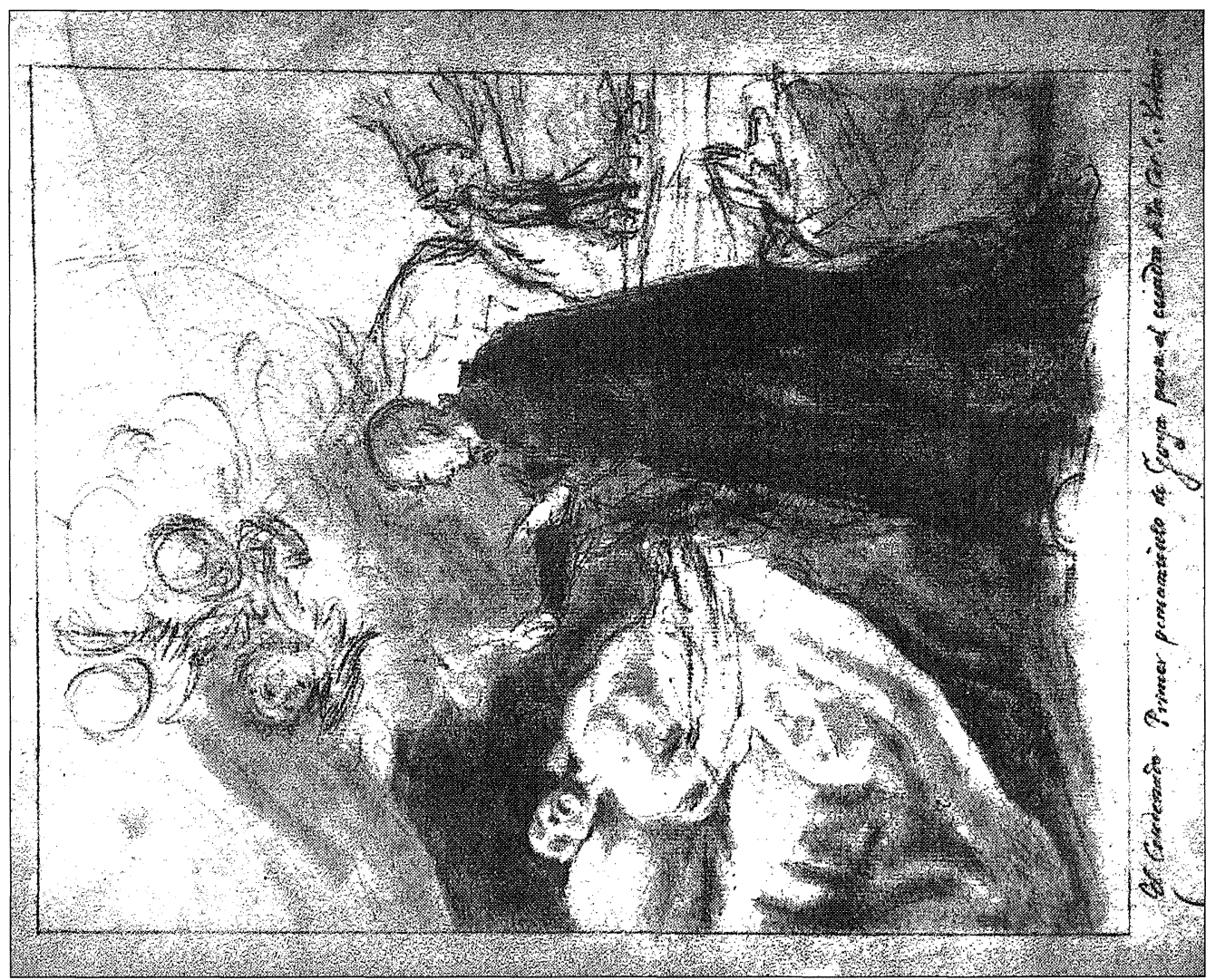


El dibujo concerniente a la despedida muestra a cinco figuras reconocibles ${ }^{9}$, en medio de las cuales dos se abrazan (fig. 2). Este dibujo ya contiene componentes esenciales del cuadro acabado, así como los motivos de las cabezas juntas, el peldaño en la parte baja de la hoja, las golillas y las botas de montar con silueta del hombre a la derecha. La ventana bosquejada en la esquina a la izquierda remite desde un principio a una disposición al aire libre. Igualmente el niño y la silueta del joven a la derecha se repiten en el cuadro aunque en otra posición (fig. 6). En el dibujo se ven representados exclusivamente hombres en trajes de época. Partiendo de estos indicios, se puede demostrar que Goya se ocupó intensamente de la biografía de su protagonista y según parece la leyó detenidamente. La primera biografía dedicada a Francisco de Borja se publicó veinte años después de su muerte y fue escrita por el hermano jesuita Pedro de Ribadeneyra; la obra tuvo gran divulgación en repetidas tiradas y traducciones ${ }^{10}$. A lo largo de su agitada vida, este santo que provenía de una familia de Grandes ocupó los cargos de virrey de Cataluña, político exitoso, consejero íntimo del emperador Carlos V, pero fue también padre de familia con ocho hijos y conoció la vida ascética de un novicio jesuita, luego sacerdote hasta General de la orden de los jesuitas.

Aunque se haya generalizado el título «S. Francisco de Borja despidiéndose de su familia», habría que precisar esto como «Despedida de sus hijos», porque de ellos es de quien se despide el padre ${ }^{11}$. En el primer dibujo ya se había tematizado un aspecto dinástico, porque el padre, antes de llegar a ser jesuita oficialmente, debió ceder sus derechos de Conde de Gandía y de cabeza de familia a su primogénito Carlos ${ }^{12}$. Pero la despedida aquí representada no es de ninguna manera el comienzo de la vida conventual y menos el adiós a la política. Lo que representa es más bien el comienzo de un viaje a Roma, que Francisco de Borja llevó a cabo en el año de 1550. Su entrada definitiva a la orden de los jesuitas se consumó un año después.

En esta escena, a la que Ribadeneyra le dedicó un extenso apartado en su descripción, se ha puesto especial ahínco en las gestiones para dejar bajo amparo sus negocios familiares, mucho antes de que Borja se decidiera por la vida monástica.

El aspecto de política familiar aún se resaltará más en el dibujo al óleo (fig. 4). Esta vez hay más figuras representadas, entre ellas dos de sus hijas recién casadas, con sus esposos y su nuera ${ }^{13}$. Los familiares se encuentran subidos en una especie de terraza de donde bajan peldaños a una no determinada profundidad en dirección frontal al espectador. Con respecto al dibujo también se ha variado la perspectiva, que presenta la escena en escorzo. En la mitad del cuadro se abrazan dos hombres, pero esta vez se han puesto de forma frontal. Esto conlleva dos consecuencias: esta vez no es el padre el que domina la mitad, sino su primogénito que además es resaltado con una vestimenta clara y fuertemente iluminada. La consecuencia lógi-

la perspectiva, los gestos o el número de figuras. Por lo tanto, este cuadro se deberá excluir como autógrafo de Goya. No es ni esbozo al óleo ni hecho por su propia mano. Esto se demuestra justamente en aquellas partes en las que el copista no entendió el modelo como, p. ej., en la barandilla de la escalera, que está mal dibujada, o en las extremidades demasiado delgadas de las figuras. Las variaciones en el esbozo se deben a que el copista no supo interpretar debidamente los efectos de las sombras y por ello utilizó contrastes demasiado endebles. Además, cometió un error de principiante al que se debe el mayor número de cabezas y la divergencia en la proporción de figuras y la arquitectura de fondo: el copista eligió un formato parecido aunque más ancho que no pudo rellenar del todo con las informaciones preconcebidas por Goya.

${ }^{9}$ En la silueta de la izquierda posiblemente se puede detectar otra figura, aunque no se puede afirmar con toda certeza.

10 Pedro de Ribadeneyra, Vida del P. Francisco Borgia, que fue Duque de Gandía, y después Religioso y III. General de la Compañía de Jesús, Madrid, 1592, 2. ${ }^{\text {ed }}$. Madrid, 1594; en versión latina por ANDreas SchotT, De Vita Francisci Borgia, libri IV, Roma, 1596, Antwerpiae 1598 así como Maguncia, 1603. La primera traducción al alemán que sigue el texto en latín de Schott por ConRad VeTter, Leben Francisci Borgiae..., Ingolstadt, 1613. Este artículo se refiere a la edición en latín, en lo siguiente se citará como RiBADENEYRA, 1596.

11 Ribadeneyra, 1596, I, cap. 17, pp. 41 sigs.

12 Ibid., cap. 16 , pp. 39 sigs.

${ }^{13} \mathrm{La}$ ausencia de la tercera hija de Francisco en el boceto se debe a que ella ya se encontraba en un convento. RIBADENEYRA, 1596, I, cap. 16, p. 40. 


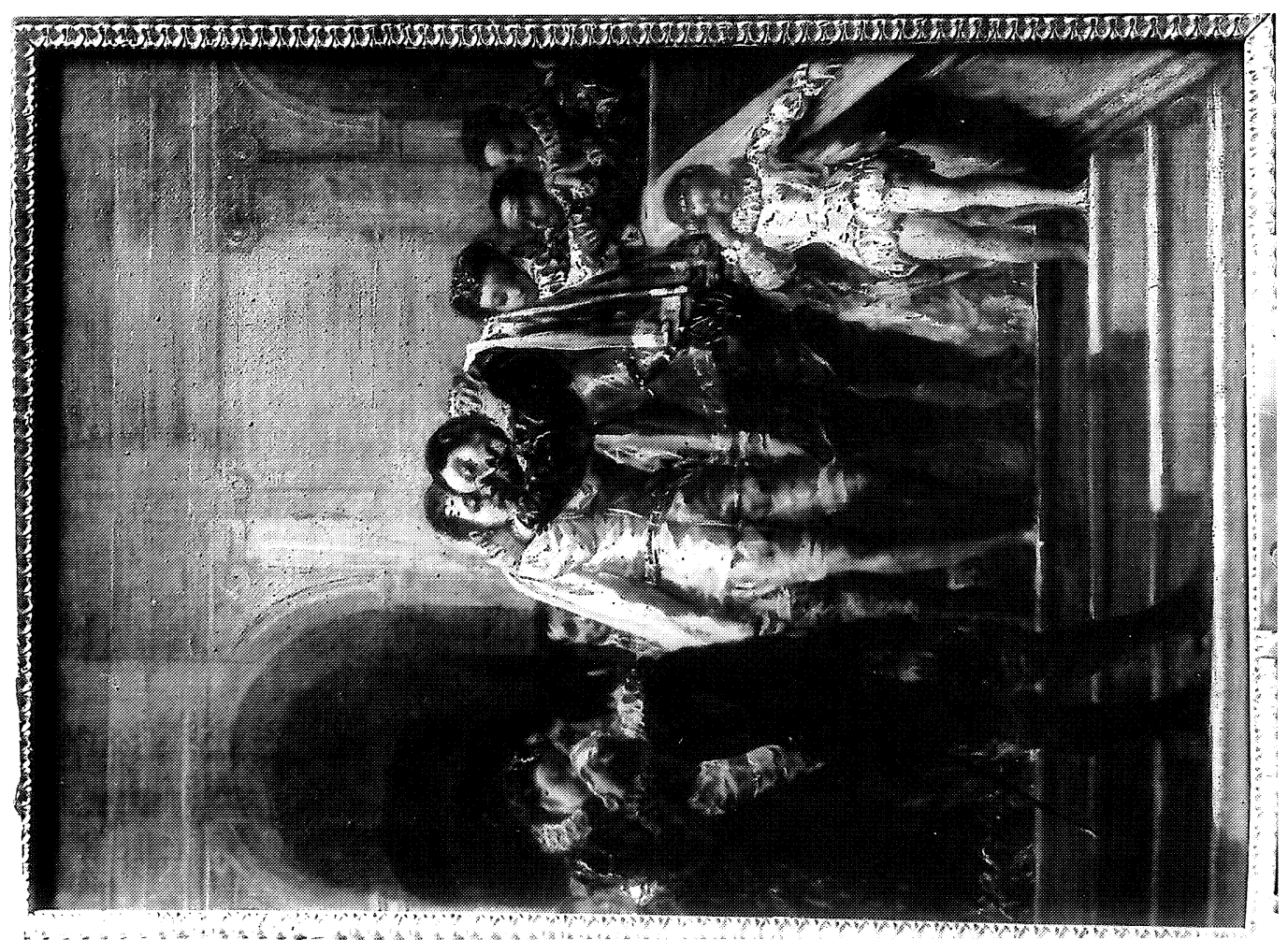

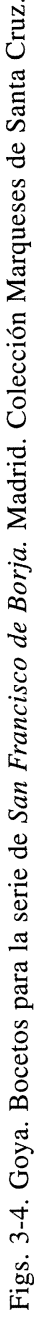

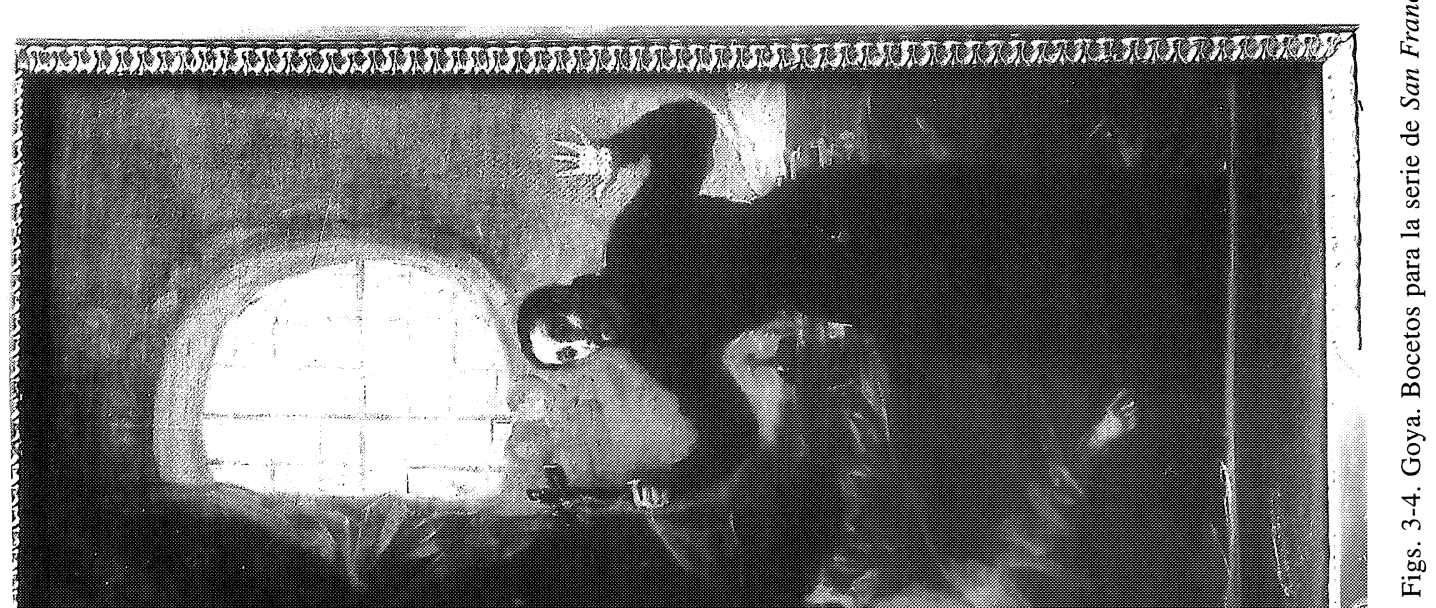


ca es que se tuvo que cambiar obligatoriamente la postura de estas dos figuras. Ya no se encuentran uno enfrente del otro, sino más bien uno al lado del otro. Los brazos están puestos alrededor del cuello del padre, que le da al abrazo un toque fraternal.

Y ello hasta tal punto que el hijo que está más al fondo sobrepasa al padre levemente y aparece ligeramente inclinado hacia adelante. Pero la posición de Francisco con sus pies bien puestos sobre la tierra demuestra que es un hombre que ve las realidades, mientras que la postura inestable del hijo denota una cierta inseguridad. La impresión de inseguridad se refuerza con la postura rígida de otro hijo que se encuentra en el lado izquierdo del boceto, que está colocado unos peldaños más abajo y que se puede ver casi de perfil.

En los cuadros al óleo las figuras son representadas de tamaño natural. Se han planteado dudas acerca de cuál de las figuras representaba al santo ${ }^{14}$, pregunta que se puede aclarar definitivamente: como en el dibujo sólo hay una figura con botas de montar con reborde y con espuela, además la fisonomía y la forma de la barba son tratados de forma parecida, como la del santo en el cuadro que le hace pareja, aunque ya no se vea nada de la espada que llevaba en el boceto.

Hay dos detalles que prueban el empeño de Goya por la mayor autenticidad histórica: los pantalones de media pierna con cuchillada y las golillas que llevan los protagonistas del cuadro ya no se usaban en tiempos de Goya; corresponden a la segunda mitad del siglo XVI ${ }^{15}$, aunque se seguía utilizando hasta mediados del siglo XVII ${ }^{16}$. Pero éstos no se encuentran en ningún otro cuadro de Goya ${ }^{17}$.

Quizá este comentario resulte marginal, pero resulta significativo para la habilidad de Goya de ilustrar con formas concretas intenciones específicas. En este caso se trata de un hecho histórico muy concreto ${ }^{18}$. Al pintor le es suficiente aludir con la vestimenta en las tres etapas del desarrollo del tema, al contrario del tratamiento del fondo arquitectónico, que en cada caso se presenta de forma distinta. Por ello es inconducente tratar de ver en el cuadro final la escalera del patio central del palacio de los duques de Gandía, en vez del palacio mismo ${ }^{19}$. La existencia de una escalera se debe a otra causa de la que hablaremos más adelante.

Se ha comentado que el cuadro resultaba ser más monumental que el boceto ${ }^{20}$. Esto se debe principalmente a la arquitectura representada, mientras que en el boceto se bosqueja en el fondo una fachada con un orden jónico que la acentúa rítmicamente, cuyos tramos más amplios no se muestran completamente, aunque sí el arco que se abre a un pasillo, a la izquierda del fondo se distingue una portada gigante, enmarcada con relieves en una pared no mayormente diferenciada. Además, la escalera no tiene una pendiente tan acentuada, como se puede derivar de la baranda que se inclina suavemente. El curso más allanado de la baranda hace posible que el hijo menor de Francisco de Borja aparezca más pequeño, ya que no puede apo-

\footnotetext{
${ }^{14}$ Fred Licht, Goya - The Origins of the Modern Temper in Art, New York, 1979, pp. 53 sigs.

15 Cesare Vecellio, Degli habiti antichi et moderni di diverse parti del mondo libri due, Venezia, 1590, II, p. 253.

${ }_{16}$ Así las repetía Goya en sus copias de las obras de Velázquez, así como las gorgueras escaroladas. Éstas debieron ser conocidas al director de la galería de cuadros de la Academia de San Fernando por otras muchas obras.

17 Manuel González Martí, «Goya y Valencia», en: Museum III, 1913, p. 431, se escandalizó a raíz de la vestimenta de las figuras: «...; que los personajes que copia no son hidalgos y caballeros del siglo XVI, sino vulgares modelos contemporáneos suyos que lejos de vestir los trajes que llevan están disfrazados en la española antigua». Pero ya el CONDE DE LA VIÑAZA, 1897 (véase nota 6), p. 79, se refirió a los trajes históricos.

${ }_{18}$ Diez años más adelante, en la decoración al fresco de la cúpula de S. Antonio de la Florida, caracterizó a la multitud con diferentes disfraces. Con esto pretendía generalizar la escena representada y darle un mensaje siempre válido. Véase al respecto Sarah Symmons, Goya. In Pursuit of Patronage, London, 1988, p. 56.

19 Ninguna de las tres concepciones arquitectónicas tiene que ver con el Palacio de Gandía. La única analogía se refiere a la barandilla de la escalera en el patio central. Pero en los detalles hay claras diferencias. Véase FOLKE NORDSTRÖM, Goya Saturn and Melancholy. Acta Universitatis Uppsaliensis, Figura Nova Series 3, Stockholm/Göteborg/Upsala, 1962, p. 64 Wilson-BAREAU y MARQués, 1993, p. 146 sig.

${ }^{20}$ Ibid.
} 
yar todo su brazo en el pasamanos, sino apenas lo alcanza con su mano. Como no ha habido cambios en la perspectiva, y sigue habiendo cuatro peldaños, el puesto del espectador resulta más distante, en consecuencia, las figuras y la arquitectura del fondo parecen ser mayores.

El dibujo con la representación de la escena en el lecho de muerte resulta ser mucho más preciso que la escena de la despedida (fig. 1). En especial, las finas líneas del marco lo acercan al formato del cuadro. Un enfermo o moribundo está recostado sobre una cama; su cabeza reposa sobre la cabecera levemente inclinada a la izquierda, sobre una cama puesta de forma oblicua con respecto al margen del dibujo. El cuerpo está desnudo, los rasgos desfigurados por el dolor, la boca está entreabierta. Delante de él se ha puesto en la mitad del dibujo el santo en perfil, que con su derecha le tiende una cruz, mientras que con la izquierda la señala.

A espaldas del santo se encuentra una mesa con recipientes, detrás de los cuales aparece un demonio alado con cabeza de gato que extiende los brazos hacia arriba y huyendo hacia la derecha da la espalda a la escena. En el tercio superior de la parte izquierda aparecen tres angelotes sobre la cabeza del enfermo o moribundo. A partir de aquí la disposición de las figuras, la cama y la mesa con los recipientes está determinada. El dibujo muestra que al principio se pensaba en representar al santo de rodillas, ya que en un segundo plano se cubrió el banquillo y se observa la rodilla inicialmente doblada.

En este caso se trató de mostrar una de las acciones caritativas del santo, que los biógrafos no se cansan de comentar. Vale mencionar la biografía publicada que se debe a Scipione Sgambata, y que apareció a raíz de la beatificación de Francisco de Borja en 1625 y que obtuvo gran divulgación ${ }^{21}$. Esta biografía realza no sólo la humildad de Francisco de Borja, sino también su asistencia espiritual como enfermero y cómo socorría frecuentemente a los moribundos ${ }^{22}$. Posiblemente esta escena del dibujo se refiera a una situación concreta en la vida del futuro santo, ya que mediante sus rezos y bajo la señal de la cruz pudo curar al monje hermano Ferdinando de Solier de una fiebre ${ }^{23}$.

En el boceto al óleo (fig. 3) hay una elaboración más precisa del interior con su ventana oval y su cortina, pero además se introducen nuevas ideas. Las proporciones de las figuras se redujeron con respecto a la imagen en su totalidad. Así las figuras se han puesto de forma análoga a las figuras del otro boceto al óleo. De esta observación deducimos que Goya ya contaba con representar a las figuras de tamaño natural en los cuadros definitivos. Además, aparece un escalón al pie del boceto, lo que permite darle la misma perspectiva que al cuadro compañero y así distanciar la escena del espectador ${ }^{24}$. Además, se ha trasladado al santo más al margen derecho y su actitud se ha cambiado rotundamente. Ahora aparece casi de frente al osbervador con los brazos extendidos en un ángulo y con un gesto de rechazo, tratando de tener a distancia algún peligro. Con la derecha agarra un crucifijo, del que salpican gotas de sangre a la sábana delgada del enfermo o moribundo. Éste está acostado casi en diagonal. El cuerpo ya está moribundo y la pierna derecha estirada sobresale del lecho. La expresión de dolor en la cara es más intensa y de la penumbra rojiza detrás de la cabeza y del cuerpo del hombre aparecen un gran número de demonios. Estos demonios tienen un aspecto convencional, que en la España

\footnotetext{
${ }^{21}$ Scipione Sgambata, Ragguaglio della santa Vita del B. Francesco Borgia, Boloña y Nápoles, 1625, p. 20. Este relato fue reeditado varias veces bajo autor anónimo, como p.ej. Milano, 1635, Parma, s.a. y Boloña, s.a.; aun después de la canonización apareció el relato con el título actualizado y con ampliaciones, así en latín: Compendium Vitae S. Francisci Borgiae, Wien, 1671; en español: Resumen de la vida y milagros de S. Francisco de Borja, Wien, 1671, y en alemán: LebensInhalt und Wunderwerck deß H. Francisci Borgiae, erstlich von P. Scipione Sgambata beschrieben, Wien, 1671; además en Roma, 1702 y en Boloña, 1728.

22 Sgambata, 1625, pp. 92 sigs.

23 Ribadeneyra, 1596, IV, cap. 4, pp. 163 sigs.

24 Si en el dibujo aún se podía percibir una buena parte del piso, esto se eliminó hasta dejar nada más que una raya y la superficie de la mesa se encuentra encima del horizonte.
} 
de finales de la Edad Media eran conocidos por los monstruos de El Bosco o también de los demonios barrocos de un P. P. Rubens. Con la presencia de estos demonios hay un cambio temático en el bosquejo de la historia.

Ya en el dibujo se observaba un demonio, pero allí éste huía ${ }^{25}$. El dibujo representaba el éxito del santo, porque un demonio huye, mientras que las cabezas de angelotes sobre la cabeza del enfermo le prometían la victoria de las fuerzas celestiales. En el boceto como en el cuadro (figs. 3 y 5) ya no aparecen los ángeles y los demonios se multiplican. Ahora pasa todo lo contrario, ellos rodean la cabecera de la cama y se dirigen hacia el moribundo y al espectador. La referencia a «La aparición de S. Juan Francisco de Regis» del Miguel Ángel Houasse, en lo que corresponde a la composición, no es más que una mera coincidencia ${ }^{26}$. El dibujo del Prado ya lleva todos los elementos compositivos que conducen al cuadro finalizado.

Para la nueva versión fue decisiva la división significativa de la escena, arriba marcada por la cortina y en la parte baja del boceto como en el cuadro retomada por la caída de la sábana más clara. La composición está dividida en una parte derecha y una parte izquierda, así que en el lado de la izquierda está el enfermo con los demonios y al lado derecho el santo con el crucifijo. Esta división se puede tomar a pie de la letra: la derecha muestra la honradez, la integridad, el lado bueno y el lado de la izquierda la torpeza y maldad. Lo que en el primer bosquejo fue presentado como un triunfo inequívoco, se ha relativizado, la lucha contra los demonios en el boceto queda indeterminada. Pero se agregó un nuevo elemento: el crucifijo del que salpican rayos de sangre en dirección al lecho y al enfermo. Además, llama la atención un detalle: la derecha de Cristo señala en la dirección del hombre sobre la cama, con la mano que se ha soltado de la cruz. Esta observación podría ser una parte indefinida en el boceto, pero este gesto se repite en el cuadro. En ninguna de las primeras biografías de Francisco de Borja se comenta este hecho. Tan sólo en el momento de su canonización ${ }^{27}$ se incluye un milagro en la leyenda de Francisco que corresponde literalmente a la escena pintada ${ }^{28}$.

${ }_{25}$ Esta observación fue ignorada por los últimos investigadores pero ya se encuentra en NoRDSTRÖM, 1962 , p. 66 (véase nota 6). Compárese, p.ej., GASSIER, 1975 (véase nota 7), n. ${ }^{\circ}$ 14, p. 42 . Se parece al ser que apareció alrededor de diez años más tarde en los dibujos preparativos para los Caprichos, especialmente el n. ${ }^{\circ} 42$ y el n. ${ }^{\circ} 106$, así como PIERRE GASsIER, Les dessins de Goya - Les Albums, Fribourg, 1973, n. ${ }^{\circ} 57$.

${ }^{26}$ Así, por primera vez, en SÁnChez Cantón, 1946 (véase nota 1), p. 294. El cuadro de Goya tiene en común con el de Houasse la cama que con su cabecera está colocada transversalmente a la izquierda en el espacio ilusionístico. Además, es comparable la postura ligeramente encorvada del santo a la derecha. Aunque la disposición general de la composición con la cama y el protagonista ya era común en tiempos de Goya (compárese, p.ej., Sebastiano Ricci, S. Gaetano y el pecador arrepentido, Milano, Brera) éste ya la había utilizado en su «Muerte de S. José» para Sta. Ana en Valladolid. La postura de Francisco de Borja en la obra concluida es el resultado de un proceso, ya que en los dibujos preparativos se resuelve de otra forma. En la labilidad encorvada Goya había encontrado una solución, que se asemejaba a la postura de la escena de la despedida. Ya en el cuadro de S. Bernardino de Siena se había decidido por una postura comparable, la que podía volver a utilizar en el Antonio en S. Antonio de la Florida variándola ligeramente (GW 1971, n..$^{\circ} 184$ y n. ${ }^{\circ} 717$ ).

27 Ya que la obra de Francisco de Borja Obras del cristiano estaba incluida en el Índice, desde 1559 su canonización se retrasó considerablemente. Se consumó por Clemente X el 12 de abril de 1671. Véase Henry Charles Lea, Geschichte der Spanischen Inquisition, 3 vols., Philadelphia, 1905, redactado en alemán por Prosper Müllendorf, Köln, 1911; reimpresión Nördlingen, 1988 , vol. 3, p. 39 sig.

${ }^{28}$ Este milagro no se menciona en las ediciones tempranas ni en la de Ribadeneyra, ni en la de SgAmBATA. También falta en Francesco SACCHINo, Historiae Societatis Jesu, pars tertia sive Borgia, Roma, 1641 y en la de JUAN EUSEBIo NiEREMBERG, Vida del santo padre y gran siervo de Dios el B. Francisco Borja, tercer General de la Compañía de Jesús, van añadidas sus obras, que no estavan impresas antes. Madrid, 1644.

Al comienzo el milagro aparece como apéndice entre los milagros póstumos de Francisco de Borja, pero ya con la advertencia que el milagro que había tenido lugar en vida del santo fue decisivo para su canonización. SCIPIONE SGAMBATA, Compendium Vitae S. Francisci Borgiae, Wien, 1671, cap. XXVII, n. ${ }^{\circ} 21$, pp. 272 sigs. Al mismo tiempo, las traducciones al español y alemán, Viena, 1671 (véase nota 21). El relato anónimo Bericht von dem gottseeligen Leben deß H. Francisci Borgia, Hertzogen zu Gandía, ..., Constantz, 1671, no es otra cosa que una traducción nueva del texto de Sgambata aunque torna referencia a la edición más antigua que aún se espera la confirmación de los milagros desde Roma. Esto va en conformidad con la edición Boloña/Nápoles, 1625 y con la edición anónima y sin fecha de Boloña. También el simario de la vida y obra de Francisco de Borja que se editó a raíz de la beatificación sólo conoce ocho milagros póstumos, no incluye 


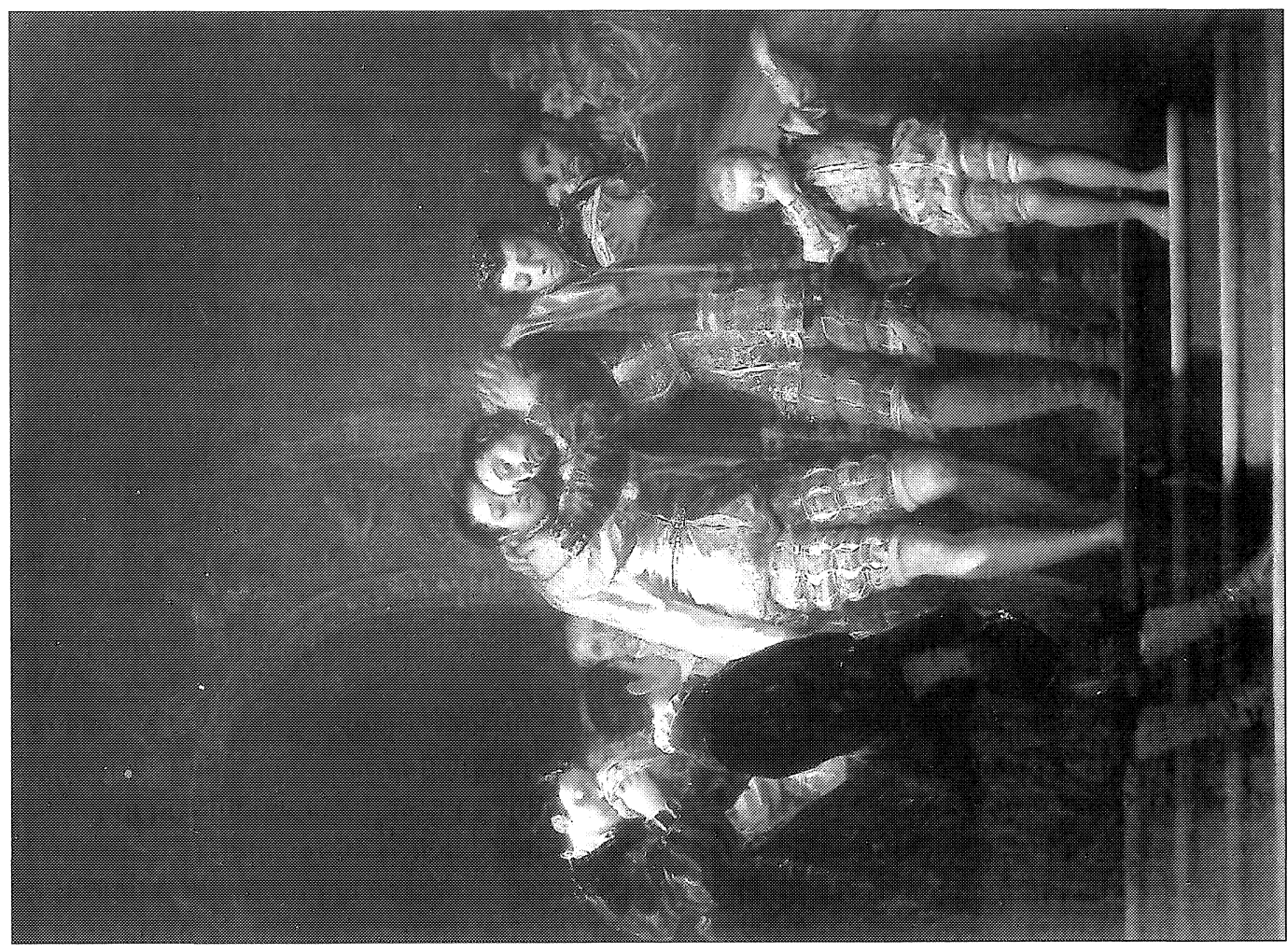

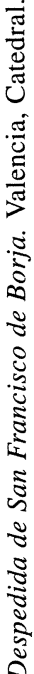

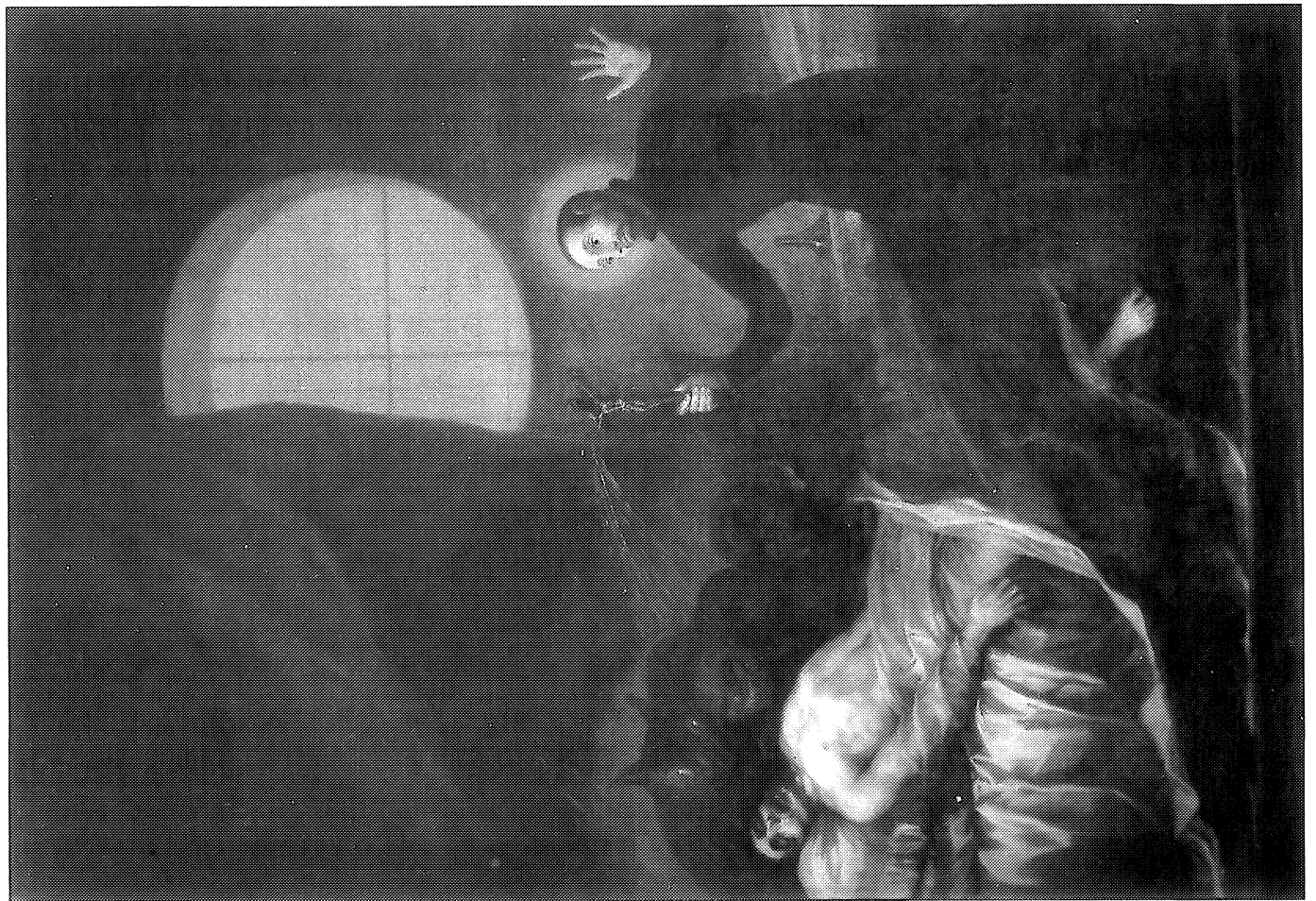


«Cristo en disfraz de Medico con el Santo va a su casa, asistiendo el Señor mientras que el Santo Padre le persuade á que se confiesse el enfermo, no ay remedio con el... Despidese Cristo, bueluese á su casa á rogar por el delante de un Cristo, y dizele desde la Cruz: Llevame allá, y tornale á pedir. Y con él en la mano lo procura, mas sin provecho; quando el cristo decladava la mano derecha (corriendo sangre de todas las cinco llagas) no oyendo ni aun las razones que le dezia Cristo, faco un puñado de sangre, y se la arrojo á la casa, diziendo al Señor: Sea para tu condenacion, pues no te quieres aprovechar della, y blasfemando de Cristo el miserable dio el alma. Qual bolveria el santo á su posada á vișta de tantos prodigios juntos!» ${ }^{29}$.

Ya que el moribundo se queda falto de fe, Goya no pudo referirse a este texto en su primer dibujo con el demonio huyendo y los angelotes jubilosos al pie de la cabeza del enfermo.

El cuadro terminado crea una mayor distancia entre los protagonistas, lo que se debe fundamentalmente a la actitud de Francisco de Borja, ya que su cuerpo, de la cintura para arriba, se inclina hacia adelante. Además, la parte superior del cuerpo va más en dirección al moribundo, para que éste pueda ver el crucifijo, que se encuentra hacia arriba y un poco más a la derecha del eje vertical del cuadro. Mientras que la actitud del santo en comparación al boceto es más tranquila y ligeramente girada hacia la derecha, el número de demonios es reducido y sobre todo se ven de frente. Los monstruos también demuestran menos movimiento. Se acentúa su presencia con su volumen reducido y su posición frontal.

El cuerpo del moribundo está descubierto hacia la cintura y su tórax está fuertemente abombado. La cara se asemeja a una calavera con sus ojos profundamente hundidos, las ventanas nasales acentuadas y los pómulos prominentes. La sangre procede de la mano de Cristo en el crucifijo y el chorro ya no cae sobre la sábana del moribundo, sino salta detrás de él y se funde colorísticamente con el brillo que rodea a los demonios que están al acecho. Este detalle no se menciona del todo en el compendio de Zelpo Serana, pero se describe de forma casi análoga en la biografía de Francisco de Borja del jesuita y cardenal Álvaro Cienfuegos ${ }^{30}$. Partien-

el "milagro de la sangre". Véase: Compendium vitae, virtutum et miraculorum nec non Actorum in causa Beatificationis et Canonizationis B. Francisci Borgiae Societatis Iesu. Ex Secretaria Congregationis Sac. Rituum, Roma, 1625, reedición Munich, 1671, pp. 15 sigs.

${ }^{29}$ Gabriel Zelpo Serana, Compendio de la vida, cirtudes, sanidad y milagros de San Francisco Borja, Madrid, 1671, p. 30 sig., nuevamente con la referencia a la importancia de este milagro para su canonización.

${ }^{30}$ Álvaro Cienfuegos, La heroyca vida, virtudes y milagros del grande S. Francisco Borja, Madrid, 1702. Esta vida de Francisco de Borja es sin duda la más extensa y se reeditó ya varias veces en el siglo xviII, así como en 1786 en Puebla/ México. También Cienfuegos se refiere a la importancia del milagro, pero no parte del relato corto de Zelpo Serana, sino en partes copia literalmente el relato más amplio de Sgambata, Viena, 1671, que además presenta con profusión de deta-

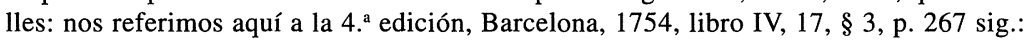

«Aviendo salido de Avila el santo Borja, dió buelta á sus Colegios, y fundaciones, arrastrado del zelo de la gloria Divina. Y entrando en una de las primeras Ciudades de España, sucedió la mas pavorosa tragedia de quantas alumbran el escarmiento desde la Historia: la qual quisiera alguno de fuesse apocrifa, pero no dexa lugar á la duda, pues la hallo repetidamente autenticada en los Processos, que sirvieran al culto, y á la Canonizacion de Borja. Estava cercano á la muerte en aquella Ciudad un Cavallero, igualmente conocido en ella por los blasones de su gran Casa, que por los escandalos de su vida, que avian endurecido su alma hasta aquella infeliz rebeldía, en que el alvedrio pone bronces á su puerta. No avia fido accessible á la eloquencia, ni á la amistad, ni á la sabiduria mas Religiosa, reducirle á que se confessasse en una enfermedad tan desesperada, obstinandose mas con el ruego, como si fuesse Villano, el que tenia los mas nobles espiritus en sus venas, y los troféos mas ilustres en su Escudo...

... Instava el Santo, temiendo, que se cansasse hasta en el bronce el sufrimiento: y Christo per cumplir abundantemente la palabra, que aviá dado á Borja, y premiar sus lagrimas con nueva demonstraciones de fineza, se hizo Predicador desde la Cruz, en que estava: porque con voz lastiméra, como que estava desangrado el aliento en la boca, bolviendo ázia el misero doliente favorable al aspecto, dixo: Advierte, ó miserable, lo que essa alma rebelde me ha costado! Mira los extremos, que haze mi amor por tu salud eterna, y por recibirte en mis brazos, y en las felicidades de la gloria, siquieres, convertirte á penitencia! Que marmol no bolveria un eco en ternura à este grito? Mas, ó bronce humano, que vives dentro de un rebelde pecho! El que avia ensordecido la razon á las vozes de su Ministro se endureció tambien á las del mismo Dueño: el qual irritado, desclavo el brazo derecho, y metiendo la mano en aquel seno prodigamente roto, sacò cerrado con 
do de este texto, también se explican las otras características del moribundo: a la rigidez y al tórax abombado y tieso se refiere la descripción en la que se reitera el endurecimiento del cuerpo, y el rostro cadavérico es el indicio de un momento concreto de la escena, el momento de la muerte y la maldición de Cristo. Hay otro argumento que sustenta la referencia a este texto específico. La alusión al Grande que había blasfemado y que se confiaba a la invulnerabilidad de su linaje sólo se encuentra en Cienfuegos ${ }^{31}$.

De esta manera el moribundo se convierte en la figura complementaria al santo. Y este contraste se representa en el cuadro hasta el último detalle; al cuerpo flexible del santo se confronta la rigidez del hombre acostado, y a los ojos grandes llenos de asombro de san Francisco de Borja, los ojos ensombrecidos del moribundo. Incluso la claridad del cuerpo es contrastada con el hábito religioso del jesuita, igual que los «nimbos» de los dos protagonistas. El brillo rojizo detrás de la cabeza del moribundo es una alusión a los fuegos infernales mientras que la cabeza del santo recibe una aureola pálida. La situación de la iluminación, que ya se aplica en el boceto, también es dual, aunque no para subrayar el contraste entre los protagonistas. Ambas figuras son iluminadas por una fuente de luz que se origina en la parte superior izquierda pero fuera del cuadro, mientras que la ventana oval sólo aparenta ser iluminada por detrás sin tener mayor efecto como fuente de luz natural para el espacio interior en el cuadro. La luz es utilizada para caracterizar el hecho milagroso. Mientras que la luz en la escena con el moribundo resulta ser irreal, en la otra escena la iluminación demuestra ser consecuentemente natural, ya que se trata de una escena al aire libre. Así que por medio de la dirección de la iluminación hay correspondencia en los dos cuadros.

Y en relación al texto de Cienfuegos se explica el cambio temático en la concepción de la escena de la despedida. En el dibujo sólo se representan hombres ${ }^{32}$, y los dos muchachos a la derecha a espaldas de Francisco de Borja parecen esperar despedirse, mientras que el padre parece negociar con su primogénito. Así se describe la despedida en Ribadeneyra, que trata de la alocución a Carlos y que no nombra a ninguna mujer y termina con la siguiente frase: «Franciscus cetereos ordine liberos complexus, valedixit» ${ }^{33}$.

En el boceto y en el cuadro se representa a mujeres, mientras que los hijos menores han cambiado su posición. La presencia de las figuras equivale a la escena de la despedida, como la describe nuevamente Cienfuegos, porque aquí el futuro santo se dirige primero a su segundo hijo Juan, que le promete obedecerle. Después de una corta conversación con su nuera a la que confía sus hijos menores, se dirige con un discurso de despedida a su primogénito Carlos. Así que la figura parada sobre las escaleras es Juan y la dama a la izquierda es la nuera ${ }^{34}$. Las precisiones en los bocetos en comparación a los dibujos se refieren de forma análoga a un texto en concreto, que el pintor aún no conocía al realizar los primeros dibujos. La disposición general

mucha sangre el puño, y se le arrojó con indignacion al ceñudo rostro denegrido, diziendo: Esta sangre, que se derramava para tu gloria, pues la desprecias, sirva para tu infelicidad eterna. Entonces aquel desdichado con un clamor pavoroso, y blasfema contra Jesu-Christo, despidió el Alma embuelta en un gemido horroroso, y fue entregada á los infames Ministros del fuego, y del espanto. Y Borja entre el horror, la pena, y el susto no acertava á moverse de aquel infeliz sitio, donde se debia fixar un colosso Gigante al escarmiento, en quien las cervices obstinadas aprendiessen á doblarse al arrepentimiento, por no exponerse infamemente al cuchillo: Y acabassen de conocer, que no bastan milagros portentosos, para arrancar del alma una costumbre envejecida, porque la desdicha se haze naturaleza, y será mas facil arrancar una de las potencias de la misma alma.»

${ }^{31}$ Cienfuegos, 1754 , p. 267, precisa además el momento exacto del milagro, ya que lo hace suceder en 1557.

${ }^{32}$ NoRDSTRÖM, 1962 (véase nota 6), p. 64, quería ver en la figura a la izquierda a una dama, pero la pierna bien visible hace descartar esta interpretación.

33 Ribadeneyra, 1596, I, cap. 17, p. 42.

${ }^{34}$ Cienfuegos, 1754, III, cap. 10, pp. 154 sigs. Al final de la descripción se lee: «De esta suerte iba la eloquencia del Duque usando del amor natural, y del arte para dexar bien impressos en la ternura del Marqués los postreros avisos, pudiendo ser aquí opportuno aquel concepto, Ars erat esse Patrem. Enmudeció el Marqués, y desprendiendose mal de aquellos brazos amorosos, fue colgado de ellos, y de su misma suspension algunos passos.» 
del espacio de la versión final ya se anuncia en los bocetos: mientras que en los dibujos para la escena de la despedida no se indica una escalera, sino únicamente un escalón, el boceto ya muestra las primeras cuatro gradas de una escalinata. Y mientras que en la escena del moribundo aparece en el dibujo, en el boceto como en el cuadro aparece en el margen de abajo un escalón; en consecuencia, estas dos imágenes desde un principio están hechas para una concepción en escorzo. En el cuadro final de la escena del moribundo el margen de abajo del cuadro es engañoso; aunque esté indicado un escalón, la primera impresión engaña, porque el santo parece actuar sobre un tablero delgado, sobre una oscuridad indefinida. El paso de los bocetos a los cuadros conlleva pocos cambios en el detalle. Mientras que en la escena de la despedida se acentúa la monumentalidad con respecto al énfasis original, la escena del moribundo muestra a un santo más fervoroso. La acción se ha reducido en los dos cuadros en relación a los bocetos, pero con intenciones diferentes: en la escena de la despedida se acentúa la monumentalidad, en la del moribundo la entrega total del santo. Los demonios también desarrollan menos actividad, ya que además es menor su número y se muestran frontalmente. Además de ello, la escena del moribundo se debe entender como una alusión general a la vida santa de Francisco: la presencia de los demonios está justificada por su mención en el texto, pero todas las biografías hacen hincapié en que Francisco tuvo que luchar repetidas veces con demonios en sus diferentes manifestaciones y que su 'humilitas' le permitía defenderse exitosamente de ellos ${ }^{35}$. Para la demostración de su 'humilitas' también sirve la escalinata en la escena de despedida. Ella representa el descenso de la esfera de la fama mundana ${ }^{36}$, además de indicar adónde se dirige el santo, porque en el segundo cuadro, junto al espectacular milagro de Cristo, no hay mayor ejemplo de humildad que el fracaso representado. La puesta en escorzo de los dos cuadros dirigidos al espectador conllevan una paradoja: al santo se le eleva por sus acciones, mientras que su 'humilitas' es el verdadero tema. Esto indica el aspecto imaginativo de la creación del pintor. Un segundo aspecto sería el sintetizar dos escenas en un contexto más genérico. Estos dos elementos demuestran que las escenas son mucho más que una sola ilustración del texto.

El paso decisivo en la concepción de ambas presentaciones ocurría en el traspaso de los dibujos a los bocetos. Y que Goya haya fundado sus representaciones en un texto concreto es el resultado de un tema problemático en el que se encontraba el pintor desde un principio. Con este encargo se vio abocado a compaginar y corresponde a las expectativas de la familia y a la postura de la política interior del rey: en tiempos en los que el rey dejaba perseguir a la Compañía de Jesús incluso después de haberla expulsado de España. Tiempos en los que se trataba de influir en el Papa para una prohibición total ${ }^{37}$, sólo se podía hacer propaganda de un santo jesuita de forma muy discreta ${ }^{38}$. Por el otro lado, había que contentar a la familia y ofrecer una imagen histórica y teológicamente inapelable. Así que la opinión, hasta ahora, de que la

\footnotetext{
35 Ribadeneyra, 1596, IV, cap. 1, pp. 150 sigs.; cap. 4, pp. 163 sigs., y cap. 5, pp. 168 sigs.; Sgambata, Boloña/Nápoles, 1625, cap. 20, p. 73 sig. Compárese también Zelpo Serana, Compendium..., $\$ \$ 98,148-153,182,271$ y 406, así como a Cienfuegos, 1754, V, cap. 1, pp. 311 sigs.; VI, cap. 2, pp. 480 sigs., y cap. 6, pp. 512 sigs., así como VII, cap. 3, pp. 562 sigs.

${ }^{36}$ De seguro no se debe a una coincidencia que a la descripción de la despedida Cienfuegos antepuso una exposición de la humildad de Francisco de Borja y además en la escena siguiente retoma el tema de la humildad. Compárese CIENFUEGos, 1754 , pp. 150 sigs. y p. 156 sig.

${ }_{37}$ Miguel Batllori, La Compañía de Jesús en la época de su extinción, en: Archivum Historicum Societatis Jesu XXXVII, 1968, pp. 201-231.

${ }^{38}$ Para Goya los jesuitas no eran desconocidos. Ya en 1765/66 trabajaba en Zaragoza su primera pintura al fresco por la compañía de Jesús: Arturo Ansón Navarro, Goya y Aragón: familia, amistades y encargos artísticos, Zaragoza, 1995, pp. 235 sigs.; y lo mismo, La formación artística de Goya y la etapa zaragozana, 1759-1774. En: JUAN J. LUNA y MARGARITA Moreno de las Heras, ed., Goya. 250 aniversario. Catálogo de la exposición, Madrid, 1996, p. 59.

Con respecto a los problemas de las imágenes utilizadas como propaganda para los jesuitas, véase IsABEL MATEO GómEZ, Dos alegorías mejicanas de exaltación de la Compañía de Jesús tras la expulsión de la orden por Carlos III, en: Departamento de Historia del Arte «Diego Velázquez». Centro de Estudios Históricos (ed.), IV. Jornadas de Arte, «El Arte en tiempo de Carlos III», Madrid, 1989, pp. 377-386.
} 
Duquesa de Osuna fue la que dio a Goya los temas de los cuadros, a partir de aquí será cuestionable.

María Josefa Alfonso Pimentel, condesa-duquesa de Benavente, fue un personaje importante, que se encaprichó en sus intereses dinásticos. Según la tradición familiar, bautizó a su primogénito con el nombre del santo, de la misma manera que ya se llamaba su padre Francisco de Borja Téllez Girón y Alfonso Pimentel ${ }^{39}$. En el mismo año de su nacimiento y a raíz de este suceso se encargó el nuevo decorado en la capilla en la catedral de Valencia ${ }^{40}$, al mismo tiempo se dio el encargo en Roma de crear una capilla en honor a los dos Papas de la familia Borja ${ }^{41}$. Pero aparte de estos intereses familiares no hay ningún indicio de una disposición temática por parte de la duquesa y el cambio dentro de la historia lo hace inverosímil. Aunque la familia pudo haber llamado la atención a Goya sobre las fuentes textuales, ya que la casa de Osuna era propietaria de una de las bibliotecas privadas más grandes de Europa, abierta al público en Madrid a finales del siglo xviII con más de 35.000 volúmenes ${ }^{42}$. Aparte del cambio temático del esbozo al boceto hay más argumentos que demuestran la no existencia de una elección iconográfica concreta por parte de los comitentes. Ya en el esbozo de la escena de la «despedida» Goya demuestra su grado de información sobre las relaciones familiares del santo; por el otro lado, el pintor, igual que en su encargo para el cuadro del altar de S. Francisco el Grande en Madrid sobre una escena de la vida de S. Bernado de Siena, sólo tenía que cumplir con pintar una escena de la vida del santo. Además, no era una excepción el dar mano libre a los pintores en la elección del tema ${ }^{43}$.

En la literatura se remite de forma unánime a los 'Caprichos', ya que hay una coincidencia formal en la representación de los demonios pero también en el contenido hay indicios que los relaciona: en ambos se pudo probar que hubo una fuente textual común como base; sin conocimiento de ella no se explica convincentemente el sentido completo de las imágenes ${ }^{44}$. Esto es un principio de configuración, que también se pudo demostrar en algunos de los 'Caprichos' ${ }^{45}$. Así que el análisis detallado de los dos cuadros de los Borja denota la conexión de texto e imagen, aunque no explica la invención, pero sí explica un elemento de configuración que en los 'Caprichos' será nuevamente utilizado. Además, la razón del significado es semejante, pero lo que en el caso de los cuadros de la familia de los Borja sólo se relaciona con el papel político de los jesuitas, en los 'Caprichos' se relacionará con muchos ámbitos de la sociedad española.

39 Ignacio Atienza Hernández, Aristocracia, poder y riqueza en la España moderna: La casa Osuna, siglos XV-XIX, Madrid, 1987, p. 111.

${ }^{40}$ Gudiol, 1985 (véase nota 6), I, cat. 244, p. 104, nombra a los hijos, pero los años de nacimiento son incorrectos: Francisco de Borja, 1785-1820; Pedro de Alcántara, 1786-1851; Josefa Manuela, 1783-1817 y Joaquina, 1784-1851. Pedro nació, sin embargo, en 1787, lo que explica el cojín en el cuadro familiar de los Osuna por Goya, ya que aún no podía estar parado con un año de edad en 1788. Con respecto al retrato familiar, véase GW 1971, n. ${ }^{\circ} 278$, p. 373.

41 María del Carmen Muñoz y Roca Tallada, Condesa de Yebes, La condesa duquesa de Benavente. Una vida en unas cartas. Madrid, 1955, pp. 128 sigs.

42 Atienza HernándeZ, 1987 (véase nota 39), p. 278.

43 Ángel Canellas López (ed.), Diplomatario de Francisco de Goya, Zaragoza, 1981, n. ${ }^{\circ} 48$, p. 236 , carta a Zapater del 25-7-1781.

44 También Wilson-Bareau, 1993 (véase nota 6), p. 150, supone que el moribundo será salvado.

45 Edith Helman, Jovellanos y Goya, Madrid, 1970, Las «Chinchillas» de Goya, pp. 183 sigs.; Nicolás Fernández de Moratín y Goya sobre «Ars amatoria», pp. 219 sigs. 